\title{
"IDEOLOGIA DE GÊNERO" E ESCOLA SEM PARTIDO: A AGENDA PRIVATIZANTE MORALIZADORA PARA A EDUCAÇÃO BRASILEIRA
}

\author{
Amanda André de Mendonçai ${ }^{\mathrm{i}}$ \\ Fernanda Pereira de Moura ${ }^{\text {ii }}$
}

\begin{abstract}
Resumo: Com o propósito de pensar dois temas que vêm marcando as discussões recentes do campo educacional brasileiro, a saber, o movimento escola sem partido e a dita "ideologia de gênero", esse texto irá tratar de tais temáticas à luz do que denominamos formação de uma agenda privatizante moralizadora da educação brasileira. Para discutir a composição dessa agenda, o artigo aborda a relação entre Estado, religião e democracia, discutindo a concepção de laicidade, a construção de um quadro conservador que se desenhou no Brasil de forma mais explícita na última década e seus contornos para a educação. Almeja-se apresentar a ingerência de diferentes segmentos conservadores, com destaque para a ação de agentes religiosos na produção das políticas educacionais recentes do país. A identificação desses agentes, suas movimentações e discursos constituem parte deste trabalho, que procura compreender parte das estratégias utilizadas, bem como identificar os principais argumentos que vêm permitindo implementar e sustentar essa agenda na cena educacional do país. Para isso, desenvolveu-se uma pesquisa qualitativa, envolvendo análise documental e levantamento de discursos que se destacaram nesse percurso. Por fim, pretendeu-se com este artigo contribuir com os estudos referentes à laicidade e à importância dessa para o campo educacional e para o estágio de democracia do país.
\end{abstract}

Palavras-chave: Conservadorismo; Laicidade; Educação; Ideologia de Gênero; Escola Sem Partido

\section{“GENDER IDEOLOGY” AND PARTY-FREE EDUCATION: A PRIVATIZING AGENDA OF BRAZILIAN EDUCATION}

\begin{abstract}
With the purpose of thinking about two themes that have marked the recent discussions of the Brazilian educational field, namely, the school without party movement and the so-called "gender ideology", this text will deal with such topics in the light of what we call the formation of a privatizing agenda of Brazilian education. In order to deal with the composition of this agenda, the article approaches the relationship between State, religion and democracy, discussing conception of secularity, the construction of a conservative framework that has been designed in Brazil more explicitly in the last decade and its contours for education. It is hoped to present the interference of different conservative segments, with emphasis on the action of religious agents, in the production of the country's recent educational policies. The identification of these agents, their movements and speeches are part of this work, which seeks to understand some of the strategies used, as well as to identify the main arguments that have allowed to implement and sustain this agenda in the educational scene of the country. For this, a qualitative research was developed, involving documental analysis and the presentation of speeches that stood out in this course. Finally, it was intended with this article to contribute to the studies concerning secularity and its importance to the educational field and to the stage of democracy in the country.
\end{abstract}

Keywords: Conservatism; Laicity; Education; Gender Ideology; Party-free Education 


\section{Conservadorismo: A "nova era" brasileira}

Com a frase "menino veste azul e menina veste rosa", a recém empossada ministra da Mulher, Família e Direitos, Damares Alves, se disse inaugurando oficialmente a chamada "nova era" na educação da gestão presidencial que se iniciou em 2019. A ministra é uma das figuras principais desta nova ordem que tem como núcleo estruturante de atuação os seguintes eixos: ataques à chamada "ideologia de gênero" nas escolas, a criminalização dos considerados "professores doutrinadores" e a defesa do "homeschooling".

O cenário em que esses três eixos se apresentam, de forma alinhada e como parte de um mesmo projeto, configuram o que consideramos como uma das formas de privatismo da educação pública, qual seja a que se relaciona com a atuação de segmentos religiosos que tentam utilizar a atuação nos espaços públicos e de poder em prol de benefícios para suas denominações religiosas ou para impor seus dogmas e orientações via educação. Trabalhamos, portanto, com a ideia de que uma das formas do Estado brasileiro promover a privatização de nossa educação se dá por meio da relação com instituições religiosas. Importante que se diga que, em geral, esse processo se constitui através de uma agenda que unifica diferentes agentes e instituições. Ou seja, a relação Estado/religião pode se desdobrar em privatismos para a educação brasileira, e esse processo ocorre em harmonia ou de forma combinada com os interesses de grupos econômicos e políticos. Entendemos que as discussões referentes aos três projetos acima mencionados: defesa do Homeschooling, a perseguição à chamada "ideologia de gênero" e aos professores "doutrinadores" são desdobramentos do que estamos denominando como agenda privatizante moralizadora.

Desta forma, esperamos que este texto auxilie na compreensão de como se deu a criação dessa agenda, quem são os agentes e instituições que dela participam, quais são seus principais interesses e como esses vêm se organizando e atuando para implementar essa agenda. Para isso, iremos ao longo do texto recorrer ao discurso construído por esses segmentos, pois compreendemos que eles nos fornecem elementos interessantes para pensarmos sobre os argumentos que estruturam e sustentam essa agenda. Segundo a ministra Damares Alves:

Nós perdemos espaço na ciência quando nós deixamos a teoria da evolução entrar nas escolas. Quando nós não questionamos, quando nós não fomos ocupar a ciência, cientistas tomaram conta e nós nos afastamos (GLOBO, jan, 2019).

Nesse seu discurso de 2013 a ministra defendeu o ensino do criacionismo nas escolas, isso é, a visão da origem da humanidade de acordo com o que conta a religião cristã. Essa não é uma fala recente, mas é de extrema relevância para a discussão que nos propomos a fazer, a de uso da educação pública para propagação de valores, dogmas e interesses referentes a alguns grupos. Alinhado ao discurso 
religioso da Ministra encontramos também o do autodenominado filósofo Olavo de Carvalho. O intelectual que inspira uma ala significativa da gestão do governo de Jair Bolsonaro, em uma de suas aulas de filosofia online, questiona uma das certezas da ciência: o heliocentrismo.

Então um cidadão chamado Albert Einstein viu isso e achou que era preferível modificar a física inteira só para não admitir que não havia provas do heliocentrismo. O fato é que, no confronto entre geocentrismo (Terra como centro) e heliocentrismo não existe uma prova definitiva de um lado, nem de outro (CARVALHO, Olavo de, Uol, 2019).

É evidente que o filósofo assume uma linha argumentativa distinta de Damares Alves, porém a defesa da relativização absoluta feita por ele em relação aos conteúdos científicos fortalece o discurso da Ministra para que o criacionismo, por exemplo, seja uma linha possível a ser ensinada nas escolas. Esse exemplo ilustra a complementariedade que existe nos discursos e ações que compõem essa agenda privatizante moralizadora.

É importante dizer que essa agenda vem sendo construída há bastante tempo, mas hoje ela se torna uma política de governo por ter sua expressão máxima como chefe do Estado. O presidente Jari Bolsonaro, imediatamente após ter anunciada sua vitória pelo Supremo Tribunal Eleitoral (TSE), fez uma transmissão ao vivo pelas redes sociais onde afirmou estar cumprindo uma "missão", onde afirmou também nunca ter se sentido sozinho, pois sempre sentiu "a força de Deus e do povo brasileiro". O presidente encerrou citando João 8:32: "Conhecereis a verdade e a verdade vos libertará".

Mencionamos o primeiro discurso oficial de Jair Bolsonaro como presidente eleito para sinalizar para outro elemento importante: a relação entre Estado, religião e democracia. Seria impossível falar dessa tríade, assim como de todas as demais questões levantadas neste texto sem discutirmos a laicidade do Estado brasileiro. Desde que essa relação entre Estado e religião no Brasil começou a ganhar novos contornos com o crescimento de setores fundamentalistas e de grupos políticos ligados a eles, Laicidade ganhou novos significados que foram fundamentais para o avanço da retórica conservadora e para o que estamos chamando de agenda privatizante moralizadora para a educação. Assim é fundamental que nos perguntemos: Somos um país laico? Que concepções de laicidade estão sendo difundidas e como elas dialogam com a educação?

\section{Laicidade: Um conceito em disputa}

O desafio de interpretar as relações do religioso com a política e com a ordem social mais ampla ao longo da história recente tem gerado grandes debates teóricos e conceituais em diferentes esferas de pensamento. De acordo com autores como Pierucci (2006) e Oro (2011), pode-se dizer que, do ponto de vista legal, não há um modelo único que rege as relações entre religião, política, Igrejas e Estado nas diferentes formações sociais. A existência dessa diversidade de modelos provoca, por certo, a necessidade 
de considerar a possibilidade de múltiplas abordagens quando se trata da discussão sobre a laicidade do Estado.

Compreendemos a laicidade como um conceito controverso e polissêmico, na medida em que envolve tanto o debate acerca da liberdade religiosa e do espaço público quanto a ideia de esfera privada e da religião como parte dela. Dessa forma, trataremos da laicidade neste texto como o elemento capaz de contribuir com uma maior imparcialidade do Estado em questões relacionadas ao mundo religioso. Ou seja, o entendimento de que um Estado laico prescindiria da religião para sua coesão social e assim não estabeleceria vínculos com as religiões.

Desse modo, estabelece-se um quadro onde a laicidade se configura enquanto um elemento constante de batalha entre inúmeros campos, alternando momentos de avanço e outros de recuo tanto das posições mais laicas quanto das religiosas. Portanto, de acordo com essa perspectiva, essas disputas são constantes e ininterruptas. A laicidade do Estado se caracteriza, assim, como um processo contínuo, que visa alcançar um estágio onde não se admite imposições de instituições religiosas para que uma lei seja aprovada ou vetada pelo Estado e seus representantes; nem que alguma política pública seja alterada devido a valores religiosos.

No Brasil, a Igreja Católica teve papel preponderante na construção do Estado Nacional o que fez com que esse processo de separação do Estado da religião em geral, e do catolicismo em particular, tenha sido bastante lento. O catolicismo marca as formas de organização e de pensamento da vida nacional de forma que seria possível estabelecer uma correspondência entre a religião católica, a sociedade e as culturas brasileiras (MENEZES, 2014).

Também há que se ressaltar que o catolicismo sempre foi beneficiado por inúmeros privilégios. Entretanto as relações entre o catolicismo e o Estado no país não foram exclusivamente de cooperação, razão pela qual se verificam, ao longo dos séculos, conflitos envolvendo a Igreja e o Estado. O reconhecimento e a manutenção dos privilégios da Igreja Católica geraram embates em diferentes campos. Em função disso, assistiu-se, ao longo da elaboração e da promulgação das Cartas Constitucionais brasileiras, sucessivas alterações quanto à relação da instituição católica e do Estado.

Para Cunha e Oliva (2009), a luta pela construção da laicidade do Estado brasileiro se fez com muitos avanços e recuos e é preciso destacar que a defesa da separação entre a Igreja Católica e o Estado, no Brasil, durante o século XIX, foi feita baseada no conceito de Estado Leigo e não de Estado Laico. Segundo os autores, "leigo não concerne ao Estado nem a uma instituição, mas a um indivíduo ou grupo de indivíduos que não dispõem de determinada formação tomada como referência”. Já laico seria o Estado "imparcial diante das disputas do campo religioso, que se priva de interferir nele, seja pelo apoio, seja pelo bloqueio a alguma confissão religiosa. Em contrapartida, o poder estatal não é empregado pelas instituições religiosas para o exercício de suas atividades" (CUNHA e OLIVA, 2014, p. 209). 
Cunha (2014a) afirma que Rui Barbosa empregou largamente o termo leigo na Constituição de 1891, que determinou a independência do Estado em relação às instituições religiosas (Idem). Essa, no artigo 72, parágrafo $6^{\circ}$, determinou: "Será leigo o ensino nas escolas públicas" e, durante quatro décadas, o ensino religioso foi substituído pela disciplina "Moral" ou "Moral e Cívica", de viés positivista. Entretanto, as primeiras décadas do século $\mathrm{XX}$ foram bastante turbulentas, com a entrada maciça de imigrantes, os movimentos de trabalhadores e os levantes militares. Fazia-se necessário defender a "ordem”, ou seja, o Estado capitalista e as hierarquias sociais.

O que assistimos, mesmo após iniciado o "processo da laicização" na Primeira República, foram disputas em torno da sustentação de privilégios para grupos religiosos e até mesmo por mais espaços desses na esfera estatal. Tal processo, portanto, não gerou o declínio da presença pública da religião e/ou a perda de prerrogativas ofertadas a determinados credos. O fato é que mesmo sendo o Brasil um Estado juridicamente apartado de qualquer instituição religiosa, não houve a quebra do monopólio religioso, ou seja, a eliminação, ou pelo menos minimização, dos privilégios facultados a grupos religiosos, o que garantiria a liberdade e a igualdade religiosa (CARNEIRO, 2017). O movimento recente tem caminhado ainda mais na direção oposta da laicização, ao expandir privilégios para um número ainda maior de grupos religiosos.

Se ao longo de toda nossa história a Igreja Católica gozou de diversas prerrogativas, incluindo a presença privilegiada no aparelho estatal, a partir da redemocratização em fins da década de 1980, outras confissões religiosas passaram a demandar essa mesma ocupação, reivindicando os mesmos benefícios garantidos aos católicos. A laicidade passou inclusive a ser defendida por esses segmentos, pela perspectiva de garantia de liberdade religiosa e de igualdade de direitos para todas as crenças, como forma de ampliação da atuação desses grupos. Assim, a laicidade, enquanto princípio apresenta-se de forma dúbia na Carta Constitucional de 1988, já que que sustenta em seu Capítulo I, que trata da Organização Político-administrativa do Estado, em seu artigo $19^{\circ}$, a separação Igreja-Estado, mas o faz de forma indireta, suscitando inúmeras interpretações tanto na sociedade, quanto no cenário político brasileiro. Segundo o documento:

\footnotetext{
É vedado à União, aos Estados, ao Distrito Federal e aos Municípios:

I - estabelecer cultos religiosos ou igrejas, subvencioná-los, embaraçar-lhes o funcionamento ou manter com eles ou seus representantes relações de dependência ou aliança, ressalvada, na forma da lei, a colaboração de interesse público (BRASIL, CONSTITUIÇÃO FEDERAL,1988).
}

Consideramos, portanto, que há uma apropriação de segmentos religiosos de parte da noção de laicidade para desenvolver um "rateamento do Estado", ou seja, para promover uma divisão e uma ocupação da esfera estatal por outros grupos religiosos e não mais apenas pelos católicos. Soma-se a isso o caso de a laicidade ser entendida e reivindicada por parte desses religiosos, não como a negação da religião pelo Estado, mas como a garantia ao acesso igualitário das religiões à esfera pública. Essa 
perspectiva, em nosso entendimento, fortalece a participação dos segmentos religiosos na cena pública brasileira e nas disputas travadas pelo campo religioso por predominância sobre os demais campos.

Quando falamos no campo educacional essa disputa é intensa e acompanha toda a história e a trajetória da educação brasileira. Nesse sentido, os dados coletados e as análises construídas ao longo da pesquisa nos levaram a concordar com Cunha (2016) a respeito da contínua interferência das religiões hegemônicas (católica e evangélicas) nas políticas públicas para educação no Brasil. Acreditamos também que a disputa por hegemonia no campo das políticas públicas para educação entre grupos mais progressistas, alinhados com as diretrizes dos órgãos internacionais como a Organização dos Estados Americanos (OEA) e a Organização das Nações Unidas (ONU), e grupos mais conservadores, próximos ao discurso produzido por grupos religiosos tradicionalistas, não esteja ocorrendo apenas no Brasil, como é o caso da Colômbia. Nesse sentido, o movimento escola sem partido seria fruto da combinação entre dois elementos: o peso da tradição da influência católica na educação brasileira e a adesão à uma nova onda conservadora, também de influência religiosa, abarcando católicos e evangélicos, que tem, em sua linguagem e nos meios empregados para divulgá-la, características mais modernas. Cunha defende a tese de que

[...] o currículo da Educação Básica, particularmente das escolas públicas, é objeto de ação modeladora que visa frear os processos de secularização da cultura e de laicidade do Estado, mediante dois movimentos, um de contenção, outro de imposição. Ambos os movimentos configuram um projeto de educação reacionária, entendida aqui como a que se opõe às mudanças sociais em curso e se esforça para restabelecer situações ultrapassadas (CUNHA, 2016, p. 2).

Segundo o autor, o movimento de contenção seria um movimento social e parlamentar e teria como sua principal arma os projetos do tipo Escola Sem Partido. Já os projetos de imposição seriam parlamentares e governamentais que propõem a inclusão das disciplinas de Moral e Cívica e de Ensino Religioso no currículo escolar. Devido a enorme mudança de cenário ocorrida de 2016, quando Cunha escreveu, e hoje, acreditamos que agora o Homeschooling e o combate a "ideologia de gênero" devem estar inseridos na lista dos projetos de contenção e que, obviamente, agora eles deixaram de ser apenas parte de um movimento social e parlamentar para serem um projeto governamental. Inclusive tendo sido plataforma de campanha. Nossa leitura é que essa tese consegue de fato abarcar boa parte do fenômeno conservador que observamos na educação nos últimos anos, uma vez que oferece uma perspectiva de interpretação mais abrangente, se compreendemos a luta contra a laicidade e a secularização ${ }^{\mathrm{iii}}$ para além da ação de segmentos religiosos, mas também empreendida por setores conservadores de maneira mais ampla e que, muitas vezes, se beneficiam ou até mesmo se apropriam do discurso religioso.

É importante mais uma vez destacarmos, que as motivações dos projetos contra a laicidade são ao mesmo tempo de ordem econômica e ideológica (CUNHA, 2016). Nesse sentido, o autor lembra que a Igreja Católica participa do mercado educacional em todos os níveis e teve papel destacado "na 
legitimação dos interesses privatistas, não apenas de seus próprios, mas de todo o setor privado, que ainda não tinha força suficiente para dispensar o patrocínio que essa instituição religiosa propiciava" (CUNHA e FERNANDES, 2012). Essa perspectiva reforça nossa percepção sobre a formação de uma agenda privatizante moralizadora para a educação que vem sendo construída principalmente no enfrentamento do que se denominou "professores doutrinadores" e "ideologia de gênero".

\section{"Ideologia de gênero": a nova caça às bruxas}

A ofensiva de lideranças religiosas e setores conservadores na educação brasileira através da temática de gênero e orientação sexual mobilizou inúmeros segmentos sociais e afetou o imaginário social através das "ameaças" que a presença desses temas na escola representaria para as famílias, para as crianças e para nossa sociedade. Em grande medida, as bases para o impacto frente a esses segmentos e para o desenrolar no campo político e no de produção das políticas educacionais, estiveram diretamente vinculadas à retórica e aos discursos produzidos por agentes e lideranças de diferentes campos na última década $^{\text {iv }}$. Por conseguinte, entendemos ser fundamental identificar quais foram os principais argumentos utilizados por esses agentes para sustentar esses discursos e suscitar o pânico moral em diversos segmentos sociais. Nesse sentido, é importante detectar esses fundamentos nas falas apresentadas, bem como caracterizá-las, buscando construir um quadro que nos permita realizar uma análise mais profunda acerca da natureza dos argumentos e o propósito de cada um deles.

No que se refere às alegações construídas e expostas nesse cenário recentemente, destaca-se a ideia de que a escola ao abrir espaço para a discussão desses temas estaria incentivando a desconstrução de uma suposta ordem natural tanto para os papéis a serem desempenhados por homens e mulheres quanto no exercício de suas sexualidades. Dessa forma, a escola também estaria impondo aos educandos o que uma coalizãov conservadora no Congresso Nacional chama de "ideologia de gênero". De acordo com seus defensores a identidade do sujeito é definida a partir do nascimento pelos seus genitais. Ou seja, não existe para esse grupo a ideia de construção social dos papéis de gênero. $\mathrm{O}$ sexo biológico (masculino ou feminino) determinaria necessariamente a identidade de gênero (homem ou mulher). Para sustentar essa noção os agentes religiosos utilizaram prioritariamente como referência "especialistas" e profissionais da área da saúde, como o Dr. Christian Schnake, médico chileno e especialista em Bioética que diz:

A ideologia de gênero é uma tentativa de afirmar para todas as pessoas que não existe uma identidade biológica em relação à sexualidade. Quer dizer que o sujeito, quando nasce, não é homem nem mulher, não possui um sexo masculino ou feminino definido, pois, segundo os ideólogos do gênero, isto é uma construção social (Ideologia de gênero: conheça seus perigos e alcances. Destrave. Canção Nova, acessado em 2/6/15). 
Apoiando-se na legitimidade dos estudos científicos ${ }^{\mathrm{vi}}$, a utilização desses discursos médicos por parte dos segmentos religiosos e conservadores tem como objetivo fortalecer um caráter "natural" do argumento apresentado. Há, na perspectiva apresentada por essa coalizão conservadora, a ideia de uma distribuição das qualidades físicas e morais baseada no gênero e uma impressão desse em sistemas e órgãos. Aliada à questão da identidade de gênero como algo inato, os conservadores também tratam a sexualidade como fruto da natureza humana, ou seja, não existiria orientação sexual, mas determinação a partir do gênero masculino ou feminino. Portanto, a ordem natural para esse grupo é a heterossexualidade. De acordo com os preceitos defendidos por esses agentes, homens e mulheres são complementares.

\begin{abstract}
Percebe-se que nada disso está presente na conjunção carnal entre dois homens ou entre duas mulheres. Falta a dualidade, a complementaridade e a fecundidade próprias do verdadeiro ato sexual. Os atos de homossexualismo são uma grosseiríssima caricatura da união conjugal, tal como foi querida por Deus e inscrita na natureza. A ideologia de gênero pretende, porém, obrigar as crianças a aceitar com naturalidade aquilo que é antinatural (CRUZ, 2014).
\end{abstract}

Outro elemento fulcral apresentado por esse grupo é o da centralidade da preservação da família. Para os agentes religiosos, em especial, a defesa do modelo nuclear de família é matriz e organizadora de suas posições:

Gênero, orientação sexual e identidade de gênero são palavras que você, certamente, já escutou onde esperaria encontrar o termo masculino e feminino. Mas cuidado, porque novos termos no linguajar social podem tentar esconder uma ideologia que visa desconstruir o modelo de família e sociedade como a conhecemos hoje (Canção Nova).

Rogério Junqueira (2017) faz uma genealogia do termo "Ideologia de Gênero". Segundo ele o padre belga Monsenhor Michel Schooyans teria sido o primeiro a utilizar o termo "ideologia de gênero" em seu livro $O$ evangelho face a desordem mundial, com prefácio do cardeal Joseph Ratzinger, futuro papa Bento XVI, publicado em 1998. Já nesse livro, a "ideologia de gênero" é apresentada como como uma ideologia da morte e uma cultura anti-família. No mesmo ano, na conferência Episcopal do Peru, é lançado o documento La ideologia de género: sus peligros y alcances, produzido pelo ultraconservador monsenhor Oscar Alzamora Revoredo, Bispo auxiliar de Lima.

Segundo Junqueira (2017) essa foi a primeira vez que o termo "Ideologia de Gênero" apareceu em um documento eclesiástico. Dois anos depois o termo apareceria pela primeira vez em um documento da Cúria Romana na publicação Família, Matrimônio e "Uniões de fato" do Conselho Pontifício para a família. Fica claro que o léxico "Ideologia de Gênero" nasce na igreja católica. Mas a enorme difusão em todo o mundo e capilaridade que encontra na sociedade se deve a união de grande parte dos setores religiosos cristãos (tanto católicos quanto evangélicos) na sua guerra santa contra o marxismo cultural, ou seja, um conjunto de ideias que buscaria por abaixo a cultura judaico-cristã ocidental. Segundo esses 
grupos, a esquerda desejaria a destruição da família, já que para o marxismo, no entendimento desses grupos, defenderia a destruição da família como condição sine qua non para a destruição do capitalismo.

A referência veemente à defesa da família por esses agentes reforça também a ideia de que a equiparação das uniões homoafetivas à condição de família seria um desvirtuamento do que a Igreja católica, por exemplo, considera como a base da sociedade. A fala do Bispo Henrique Soares, Titular de Acúfica e Auxiliar de Aracaju, de que a Igreja não tem "nada contra os homossexuais, mas tudo contra ao fato de que isso seja considerado família e que venha, a partir daí adoção de filhos e, assim, o conceito familiar seja tão dilatado", ajuda a entender como tais argumentos são apresentados.

A máxima cristã de que Deus criou o homem e a mulher para "crescer e multiplicar" foi amplamente reforçada nesse processo de enfrentamento ao "perigo" trazido pelas "feministas de gênero"vii e pelos "ideólogos de gênero"viii no que tange a preservação deste pilar de sustentação do cristianismo, a instituição família. Tal defesa foi feita por diversos setores cristãos, com destaque para a atuação das lideranças e membros do alto clero da Igreja Católica. O Papa Francisco, por exemplo, em entrevista conferida em 2015, ao referir-se à "ideologia de gênero" afirmou que essa seria contrária ao plano de Deus, um erro da mente humana que provocaria muita confusão e atacaria a família. Nesse mesmo discurso o pontífice lamentou "a prática ocidental de impor uma agenda de gênero a outras nações por meio de ajuda externa", chamando isso de "colonização ideológica" e comparando-a à máquina de propaganda nazista. Para explicar tal comparação ele apresentou um exemplo de 1995 quando, disse ele, uma ministra da educação de uma região pobre foi informada de que ela poderia ter um empréstimo para construir escolas, contanto que essas utilizassem livros que ensinavam a "ideologia de gênero", o que configuraria um caso de "colonização ideológica", ou seja, "coloniza-se as pessoas com uma ideia que quer mudar uma mentalidade ou uma estrutura".

É importante resgatar que as condenações do Papa Francisco à "ideologia de gênero" seguiram os passos do Papa Bento XVI, que abordou o tema a partir da ideia de "profunda falsidade" dessa ideologia e da "revolução antropológica contida nela". Em dezembro de 2012, Bento XVI referiu-se, num discurso à cúria romana, ao uso do termo gênero como um pressuposto de uma "nova filosofia da sexualidade", onde as pessoas se oporiam à ideia de que elas têm uma natureza, dada por sua identidade corporal, que serviria como um elemento definidor do ser humano.

No Brasil, as falas e posicionamentos desses agentes da cúpula católica repercutiram de sobremaneira, assumindo um vulto considerável e conquistando no Movimento Canção Nova ambiente propício e apto para a organização de uma retórica em torno dessa temática. Os Bispos católicos do Estado de São Paulo declararam que "as consequências da introdução dessa ideologia na prática pedagógica das escolas contradizem frontalmente a configuração antropológica de família, transmitida há milênios em todas as culturas". Isso significaria submeter, para eles, as crianças e os jovens a um 
processo de esvaziamento de valores cultivados na família, fundamento insubstituível para a construção da sociedade. Verifica-se, portanto, nos pronunciamentos e no arcabouço teórico defendido por segmentos católicos a heteronormatividade e a noção de família nuclear como pilares de sustentação da fé cristã. Propostas e segmentos que visem a desconstrução dessas noções são entendidos como tentativas de desarticulação do cristianismo. Essas abarcariam desde a defesa de políticas de inseminação artificial, venda de embriões, à liberação da pílula do dia seguinte abortiva, "camisinhas" nas escolas, barriga de aluguel, células embrionárias, transitando pela liberdade da expressão artística, o mal que fazem as novelas, o perigo de alguns movimentos sociais, chegando até a ideia de cristofobia, ou seja, a perseguição aos cristãos, o laicismo e a expulsão de Deus da sociedade.

Cumpre mencionar o papel precursor da Igreja Católica na batalha encampada contra o "gênero" e sua articulação com as políticas públicas. Nesse sentido, diversas instituições, governos, partidos, movimentos e lideranças tornaram-se alvo de ataques de parcela da instituição católica como sendo responsáveis pelo risco que a existência das famílias estaria correndo. Alguns agentes, como Felipe Aquino $^{\text {ix }}$, chegaram a acusar organizações como a Organização das Nações Unidas de quererem destruir a família natural, constituída por um pai, uma mãe e seus filhos (AQUINO, 2012).

Também é importante destacar a atuação dos agentes evangélicos na constituição dessa retórica conservadora e contrária à "ideologia de gênero". Marisa Lobo ${ }^{\mathrm{x}}$, uma das agentes mais atuantes dessa coalizão conservadora afirmou, por exemplo, que:

A vitória da ideologia de gênero significaria a permissão de toda perversão sexual (incluindo o incesto e a pedofilia), a incriminação de qualquer oposição ao homossexualismo (crime de "homofobia"), a perda do controle dos pais sobre a educação dos filhos, a extinção da família e a transformação da sociedade em uma massa informe, apta a ser dominada por regimes totalitários (LOBO apud MARTINS, 2014).

E acrescentou:

\begin{abstract}
Muitos brasileiros ainda não entenderam o perigo da ideologia de gênero. Políticos querendo ser politicamente corretos em época de eleição estão condenando o Brasil a uma farsa que vai promover a maior guerra de gerações jamais vista. E aqui chamo a atenção também das lideranças religiosas, que tem um papel fundamental de alerta e esclarecimentos de seus membros e se fecham em suas igrejas de forma egoísta. Líderes que se alienam por vontade ou por omissão e não querem discutir o assunto, colocando em risco a própria igreja, pois não preparam os membros para conviver sem se contaminar com essas ideologias farsantes (LOBO apud MARTINS, 2014).
\end{abstract}

Se os católicos iniciam os ataques à categoria gênero, e cunham a expressão "ideologia de gênero", os evangélicos - através de algumas denominações e uma parcela significativa de agentes - não ficaram para trás. O crescimento demográfico e político exponencial experimentado por algumas de suas denominações nas últimas décadas, vem sendo acompanhado de enfrentamentos públicos aos direitos sexuais e reprodutivos das mulheres e a perseguição à população LGBT. Nessas pautas tem se 
estabelecido uma unidade de ação com os católicos - a despeito da disputa por fiéis no campo religioso o que vem garantindo, por meio da junção de capitais desses segmentos, o fortalecimento da coalizão conservadora no Congresso Nacional na chamada Bancada da Bíblia.

Cumpre sublinhar a atuação desses agentes através das redes sociais. Diversas lideranças religiosas e figuras que pertencem a esse círculo tiveram uma atuação preponderante em seus canais de TV, na internet e em suas colunas, contribuindo de sobremaneira para a disseminação da retórica conservadora e para a vitória destes segmentos na disputa em curso naquele momento. Um dessas figuras foi o pastor Silas Malafaia que declarou:

Tem algumas feministas que se assustam quando a gente fala que a autoridade pertence ao homem e elas não sabem definir o que significa autoridade (...) E agora querem destruir as figuras da família, a desconstrução da heteronormatividade e a desconstrução dessa família nuclear. E nós vamos ver o que vai acontecer nas gerações futuras, o desarranjo social (KOREN, 2015).

No Congresso Nacional, especialmente na Câmara dos Deputados, os evangélicos protagonizaram com discursos inflamados na tribuna a empreitada contra o "risco" da "ideologia de gênero". A unidade constituída entre esses e os católicos configurou-se de forma que agentes de ambos os segmentos atuavam na mobilização nas redes sociais, líderes católicos do alto clero pressionam as lideranças de partidos políticos e bancadas - com uma atuação de bastidores e daqueles que ao longo de toda história do país circularam pelo aparelho estatal e as instâncias de poder- com as performances do plenário. Essa última contou com agentes católicos, mas sem sombra de dúvida teve como ator principal agentes evangélicos:

Se a família tradicional, assim como os papéis de gênero convencionais, são [sic] tanto naturais quanto de origem divina, qualquer discussão está encerrada. A ordem natural e divina é, por definição, incontestável. O discurso culmina então na defesa de valores que deveriam ser fixos, mas estão sendo "invertidos" e "trocados" (PASTOR MARCO FELICIANO-PSC, sessão de 25/2/2016).

Vale destacar também a figura de Dom Orani João Tempesta, central na mobilização católica, por exemplo, contra a presença do termo gênero no Plano Nacional de Educação - PNE, tendo realizado diversos pronunciamentos sobre o tema em diferentes frentes, escrito textos e artigos veiculados amplamente e atuando no lobby junto a parlamentares na Câmara Federal. Outra atuação católica notória foi a da Renovação Carismática Católica, que também exerceu concomitantemente forte influência em representantes políticos e na sociedade civil, fato de extrema relevância para a vitória da coalizão conservadora no PNE.

A despeito de toda a resistência que vem sendo apresentada, é sabido que a supressão da referência a gênero e orientação sexual vem sendo efetivada, não apenas nos planos de educação, mas em conteúdos programáticos, em livros didáticos e em planos de aulas. Há uma vitória dessa coalizão conservadora. São inúmeros os fatores a serem considerados numa análise sobre essa disputa e a vitória 
dos conservadores. Pelos limites estabelecidos por este trabalho não iremos abordar todos eles, mas consideramos relevante elencar alguns deles, como a atuação em rede e na rede de segmentos cristãos, para divulgar seus argumentos, convocar o apoio dos fiéis, difamar e acompanhar as ações dos opositores (VITAL DA CUNHA, 2014) e o desempenho tímido da parcela da sociedade civil e dos grupos prólaicidade frente aos embates com esses segmentos.

A fragilidade de algumas dessas organizações sociais para realizar tais enfrentamentos, a pouca capilaridade em suas bases sociais e o poder de mobilização frente às mesmas também contribuíram, a nosso ver, com esse quadro de fortalecimento dos conservadores. Além disso, é possível verificar ao longo da trajetória do campo de produção de políticas educacionais, que as pautas relacionadas à laicidade muitas vezes acabam virando "moeda de troca" de parte dessas organizações com os setores religiosos em vistas a garantir a aprovação de outros projetos considerados mais relevantes, o que desgasta e enfraquece os grupos que permanecem na disputa.

Assim, é possível entendermos como no campo de produção das políticas educacionais há hoje uma supremacia da retórica contrária à aliança entre gênero e educação. Ou seja, o volume de capitais dos agentes da coalizão conservadora e suas ações na cena pública brasileira, num período recente, especialmente através de discursos que sustentam um pânico moral na sociedade, vêm permitindo que esses imprimam a lógica de uma educação considerada "neutra" e baseada em conteúdos gerais e técnicos, onde a família e a religião determinam quais valores éticos e morais são ensinados aos estudantes, na elaboração e produção das políticas públicas.

\section{O Escola sem partido e os chamados "doutrinadores"}

A liberdade de ensino vem sendo ameaçada no Brasil com o crescimento e o acirramento dos debates e da organização envolvendo o movimento Escola Sem Partido. Tal movimento utiliza o discurso de suposta neutralidade ideológica, de pluralidade e diversidade de ideias na escola, para na verdade colocar no cenário educacional brasileiro projetos de viés conservadores, obscurantista e reacionários. Esse grupo vem atuando no Congresso Nacional, nas assembleias legislativas, nas câmaras municipais e especialmente nas redes sociais. Por meio de um discurso que acusa os professores de estarem utilizando sua liberdade de ensino para doutrinar e manipular crianças e jovens, esse movimento vem mobilizando pais e mães preocupados com a educação que suas filhas e filhos recebem.

A partir da narrativa de doutrinação realizada pelos professores esse movimento defende como estratégia aprovar Projetos de Lei que visem coibir o que chamam de processo de "ideologização" dentro da sala de aula. Com esse intuito, o movimento Escola Sem Partido criou a minuta do Projeto de Lei Programa Escola sem Partido, que serve de base para qualquer parlamentar que se disponha a apresentá- 
lo nas casas legislativas em qualquer instância da federação. Importante destacar que o pedido de criação de um projeto de lei foi feito pelo deputado estadual Flavio Bolsonaro (PSL-RJ) ao advogado Miguel Nagib criador e coordenador do movimento. Dessa forma, o Escola Sem Partido deixou de ser "apenas" um movimento social (que existe desde de 2004) para ser também um modelo de Projeto de Lei (2014) ${ }^{\mathrm{xi}}$.

Já foram apresentados mais de $200 \mathrm{PLs}^{\mathrm{xii}}$ de censura em todo o Brasil que tramitam ou tramitaram no Congresso Nacional, nas Assembleias Legislativas estaduais e nas Câmaras Municipais. Dentre as proposições apresentadas existe até mesmo previsão de cadeia para docentes prevista pelo PL 1411/2015 da Câmara dos deputados. Tais projetos preveem também a interferência na grade curricular e em materiais didáticos das escolas.

Segundo seus defensores "os pais têm direito a que seus filhos recebam a educação religiosa e moral que esteja de acordo com suas próprias convicções". Segundo o PL, "cabe aos pais decidir o que seus filhos devem aprender em matéria de moral" e "um Estado que se define como laico - e que, portanto, deve ser neutro em relação a todas as religiões - não pode usar o sistema de ensino para promover uma determinada moralidade, já que a moral é em regra inseparável da religião"xiii. Essa mesma argumentação é repetida por Nagib em uma audiência pública na qual ele afirma:

\begin{abstract}
Isso é muito importante, o princípio da Laicidade do Estado por que muitas vezes é invocado para justificar o uso do sistema de ensino para promover, por exemplo, coisas como a ideologia de gênero. Dizem: O Estado é laico então não venham tentar impedir os professores de transmitir aos alunos esses conceitos. Mas vejam bem, as religiões não são formadas apenas de cultos, de narrativas e ritos. Elas também possuem a sua moralidade. O cristianismo possui a sua moralidade. Não existe cristianismo sem moral cristã. Se o Estado puder usar a sua máquina para promover uma moralidade que seja hostil a moralidade cristã ele estará violando justamente o princípio da laicidade do Estado por que ele estará deixando de ser neutro em relação àquela religião que ele está hostilizando. A moral da religião que ele está hostilizando. Não existe cristianismo sem moral cristã. E os cristãos brasileiros, a imensa maioria deles, é obrigada a mandar os seus filhos pra escola. Se um professor ateu, puder usar, ou militante, ativista, puder se valer da presença obrigatória dos alunos para impor aos alunos uma moralidade contrastante com a moralidade da família, ou com a moralidade cristã, ele estará perseguindo a religião cristã, estará ferindo o preceito da laicidade do estado (AUDIÊNCIA PUBLICA).
\end{abstract}

Vemos então novamente uma disputa em torno dos significados de laicidade que, na visão do Escola Sem Partido, em último caso, sustentaria a própria possibilidade do indivíduo se insurgir contra a laicidade se esta for uma demanda da sua religião.

O Escola Sem Partido, portanto, concebe o professor como "agenciador ideológico e partidário" e os alunos como "audiência cativa e vítimas passivas de agentes ideológicos". Essa é uma noção que vem sendo amplamente combatida pela educação crítica e progressista, de que estudantes são desprovidos de ideias, pensamentos próprios e que são por isso, conforme o projeto por eles defendido, "folhas em branco". Segundo esse movimento os alunos não são capazes de refletir, são seres passivos e colocados como "vítimas". Nagib já chegou a comparar os professores a estupradores para tentar defender esse seu ponto de vista: 
Por fim, com relação ao problema da... e é um argumento surrado... o de que o aluno não é uma folha em branco. Uma criança de 12 anos de idade sabe perfeitamente como dialogar com o professor, com o professor tarimbado, com o militante, que eles estão ali em pé de igualdade. Bem, é evidentemente como disse o professor (?) um argumento de gente sonsa. Com todo o respeito. E mais, é um argumento que é típico, é típico, dos abusadores, que procuram minimizar a gravidade dos seus atos apelando para a condição pessoal das suas vítimas.

Digo mais, é um argumento típico também dos estupradores que alegam em sua defesa que aquela menina de 12 anos que eles acabaram de violentar não é tão inocente quanto parece. Este é o argumento de que o aluno não é uma folha em branco. Então este argumento precisa ser varrido por um a questão de honestidade intelectual (AUDIÊNCIA PÚBLICA).

Este é o primeiro de muitos pontos extremamente graves defendidos por esse grupo. Mas esse talvez seja à base de sustentação dos demais argumentos apresentados. A ideia de alunos e alunas desprovidos de senso crítico, ou mesmo de personalidade, e prontos para serem "preenchidos" pelos ideais dos professores, alimenta a concepção de escolas como fábricas de doutrinação. O que esses projetos fazem, portanto, é criar o factoide da possibilidade de neutralidade do docente para garantir que esse aluno passivo não se torne "vítima" de um processo de ideologização. Para isso, é necessário desconstruir a ideia do professor como um ser social, um agente político e um intelectual. Ou seja, aquele que tem posição e base ideológica, mas que trabalha fornecendo ferramentas intelectuais para o aluno desenvolverem suas próprias bases ideológicas, como sugere o "Escola sem partido", fazendo “doutrinação". conceito, aliás, empregado até nos projetos de lei, sem que seja explicitado o seu significado.

O que esse discurso da neutralidade sustenta, na verdade, é a conservação do modelo de educação vigente. Uma educação excludente, desigual e acrítica. Além disso, essa suposta neutralidade também serve para limitar e cercear a atuação dos professores, já que qualquer tema que não seja consensual, que possa mexer com convicções familiares, fatalmente fará com que o professor ou a professora sofram a acusação de um suposto crime de manipulação ideológica. E esse é outro ponto importante da atuação docente que está sendo ameaçada por esses projetos. O constrangimento à liberdade dos professores escolherem aquela que consideram a melhor abordagem sobre um determinado tema. Em geral, seus defensores desqualificam a escola como lugar de formação da cidadania, promoção de valores democráticos e respeito aos Direitos Humanos. Portanto, os temas ligados à diversidade, às questões raciais, de gênero e orientação sexual seriam os principais pontos a serem retirados do espaço escolar por esses projetos.

É interessante observar que a maioria dos seus proponentes não são professores e não conhecem de perto o que acontece nas salas de aula. Não sabem dos principais debates envolvendo o campo educacional, mas preocupam-se em garantir a oferta de uma educação conservadora e que não ameace o projeto de sociedade que os integrantes do "Escola sem partido" constroem. Ou seja, o interesse desse grupo na educação passa pela manutenção do status quo. 
Também é fundamental relacionar o quanto esse projeto, que independente de seu reconhecimento legal para existir, - e com isso destacamos o fato de que o Escola sem Partido não foi aprovado enquanto legislação ainda - está presente nos relatos do cotidiano escolar em todo o país que são de vitória desse projeto, pois professores estão sendo perseguidos e acusados de doutrinação constantemente. Há ameaças e tentativas de conter a abordagem de inúmeras temáticas, o que configura mais uma vitória do que neste texto chamamos de agenda privatizante moralizadora. Compreendemos o Escola sem Partido como um dos eixos estruturantes dessa agenda, tanto por propor um caráter "moralizador" para a educação pública, quanto por relacioná-la com diversas formas de privatização do ensino ${ }^{\text {xiv }}$. Essa agenda, para nós, se intensifica após a última eleição presidencial e a vitória de Jair Bolsonaro.

\section{O governo Bolsonaro: o MEC em guerra}

O controle sobre a pasta da educação sempre se mostrou como um dos principais pontos de disputa durante as corridas políticas em curso. Em grande medida isso se deve ao volume de recursos que o MEC dispõe que a faz ser cobiçada por diferentes grupos, mas também pelo espaço de articulação política, de implementação de projetos e de agendas que ele permite. Como sabemos, ao longo da disputa presidencial, Paulo Guedes ${ }^{x v}$, foi mobilizado como uma espécie de tutor de Bolsonaro durante a campanha. A linha utilizada foi a de interdição de debate entre as pessoas que já declaravam sua intenção de voto em Bolsonaro. Já os setores cristãos fundamentalistas e os setores judaicos ligados ao sionismo precisavam ser convencidos a embarcar nesse projeto que abarcava também o agronegócio e a indústria armamentista. O delicado equilíbrio entre os grupos obviamente só poderia ser conseguido, pelo tradicional loteamento de cargos nos ministérios e o MEC sem dúvida era uma das cerejas do bolo. Exemplo disso, foi a demora na divulgação do nome de quem seria o chefe da pasta. Até a confirmação oficial, inúmeros nomes foram ventilados e a repercussão de cada um deles entre a base de apoio do governo foi avaliada.

O nome finalmente divulgado foi o de Ricardo Velèz-Rodrigues. Cumpre mencionar que Velèz parece ter sido o nome encontrado pelo governo para agradar de uma vez a diferentes grupos que apoiam e sustentam o governo. Contudo, o mesmo não tinha ligação com Olavo de Carvalho, figura de referência para o governo, conforme já mencionado neste texto. Velèz se caracteriza por ser um fundamentalista cristão, conservador e ter fortes e longos vínculos com o exército, em ao mesmo tempo que defende a agenda liberal. Formado em Teologia ainda na Colômbia, onde nasceu, continuou a sua formação no mestrado e doutorado em Filosofia aqui no Brasil, onde se naturalizou. Como aponta Rodrigo Jurucê, se Velèz possui vínculos com Olavo de Carvalho esses parecem ser relativamente recentes em comparação com o vínculo que esse tem com Paulo Paim, que foi seu orientador do mestrado. Paulo Paim e Paulo 
Mercadante foram da segunda geração do Instituto Brasileiro de Filosofia (IBF), criado em 1949 por Miguel Reale e que funcionou até os anos 90.

O IBF foi um ThinkTank da direita que conseguiu difundir bastante suas ideias na sociedade brasileira. Como lembra Jurecê ${ }^{\mathrm{xvi}}$, Miguel Reale dedicou boa parte de sua obra a pensar formas de enfraquecer ou limitar o voto popular inclusive pelo mecanismo do impeachment. Provavelmente, por algo além de coincidência, seu filho, Miguel Reale Júnior foi autor com Hélio Bicudo e Janaína Paschoal, do pedido de Impeachment da então presidenta Dilma Rousseff. Foi na Revista Brasileira de Filosofia publicada pelo instituto, que Velèz publicou boa parte de sua vasta obra. Como lembram Calil e Jurecê, nela é constante a crítica ao que Velèz chama de "dominação cientificista" do Brasil. Lembram também que o termo ficou famoso por constar de seu texto "Um roteiro para o MEC" escrito pelo ministro como uma espécie de carta de intenções para acalmar a base bolsonarista quanto a indicação de seu nome. Nela o ministro acenou aos diferentes setores que compõe essa base sobre sua intenção de agradar a todos. Foi dessa forma que Velèz desbancou nomes como o ultraliberal Stavros Xanthopoulos ${ }^{\text {xvii }}$, Mozart Neves, do Instituto Ayrton Senna e Guilherme Schelb, o procurador da República com profundos laços com o Escola Sem Partido e contra a "ideologia de gênero". Por fim, a "dominação cientificista" no Brasil para Velez seria, segundo Jurucê, a "crença" de que questões sociais e políticas poderiam ser solucionadas de forma cientifica ou baseada na ciência o que se configuraria em uma tradição despótica do Brasil.

Entretanto, é provável que no afã de agradar todos os segmentos de sua base o governo tenha acabado por escolher uma figura com pouca capacidade de atuação política e que demonstra total desconhecimento e despreparo para o cargo. O processo de "despetização" operado dentro do MEC, com inúmeras exonerações seguido de indicações de nomes ligados ao fundamentalismo religioso tornou o ministério completamente inoperante. Ao final de apenas 3 meses de governo os grandes grupos de mídia já escreviam chamadas como “depois de 15 exoneração, medidas polêmicas e seis recuos, o Ministério da Educação (MEC) está à deriva"xviii.

Um dos recuos mencionados diz respeito justamente às disputas a respeito do sentido de Laicidade e à defesa dessa como uma distribuição equânime de recursos entre as religiões. Sendo assim, já que o ministro é católico caberia que inúmeros outros postos ${ }^{x i x}$ dentro do ministério ficassem a cargo de evangélicos. Foi assim também que Iolene Lima foi convidada e desconvidada para ser a secretária executiva do MEC, ou seja, a número dois do ministério. Iolene, além de pastora, também é a criadora e ex-diretora de uma escola cristã no interior de São Paulo que segundo ela própria só possuía professores e funcionários evangélicos e onde a educação é "baseada em princípios, ou seja, baseada na palavra de Deus. É uma cosmovisão cristã". Segundo a pastora, em sua escola

O aluno aprende que o autor da história é Deus. O realizador da geografia é Deus. Deus fez as planícies, fez os relevos, fez o clima. O maior matemático foi Deus. (...) Os alunos menores de primeiro ano, o primeiro contato que eles têm com a matemática é pelo livro de Gênesis. É todo o 
currículo escolar organizado sob a ótica das Escrituras. Elas não limitam o conhecimento, mas é a partir delas que o professor invade as áreas do conhecimento e apresenta o conhecimento formal para os alunos. (...) Somente em Cristo nós podemos educar bem ${ }^{\mathrm{xx}}$.

Após a divulgação desse vídeo e da descoberta que a indicação de seu nome teria vindo da primeira-dama Michele Bolsonaro, a pastora precisou ser desconvidada para o cargo. E o ministro da educação, segundo ventilado na imprensa, mesmo permanecendo no cargo, não pode nomear mais ninguém. Um ministro da educação sem poder político e sem conhecimento da pasta, um zig-zag tanto nas nomeações quanto nas exonerações, inclusive do próprio Velèz, e uma enorme instabilidade marcaram os primeiros meses de gestão Bolsonaro a frente do Ministério da Educação. Se há dúvidas sobre a guerra em curso no MEC em torno dos diferentes grupos políticos, econômicos e religiosos que apoiaram e sustentam o governo e a busca por hegemonia, em contrapartida não há dúvida de que esses grupos se conectam na agenda privatizante moralizadora para a educação.

\section{Conclusões}

É essencial dizer que fazemos referência à laicidade como processo, como construção histórica e não como uma linha contínua. Nesse sentido, falar em Estado laico implica em considerar que há contradições que ficam atenuadas ou que são acirradas, que há momentos de maior apartação do Estado em relação às questões afetas ao mundo religioso e outros de estreitamento desses. Ou seja, tal concepção de laicidade pressupõe conflito e disputa nessa relação. É possível identificar, então, ao longo da formação histórica, social, cultural e política de nosso país momentos mais laicos e ocasiões de retrocesso nesse distanciamento entre Estado e religião. Assim, acreditamos ser possível afirmar que o conceito de laicidade se torna correlato ao de democracia, onde também existem recuos e avanços no seu percurso de construção. Bem como não é possível existir laicidade sem democracia e vice-versa.

Importante considerar que no Brasil o avanço dos movimentos feministas e pela diversidade sexual se deu simultaneamente ao crescimento dos grupos tradicionalistas católicos e neopentecostais, o que por certo conforma um campo de tensões entre esses segmentos. Soma-se nessa análise o capital religioso, sua transformação em capital político e quais as consequências desse deslizamento entre as fronteiras das esferas política e religiosa para a nossa democracia. Uma das consequências desse processo é ocupação massiva de religiosos na esfera estatal. Mais uma vez lembramos que essa presença não foi inaugurada pelos evangélicos - afirmação recorrente no senso comum - mas sim ampliada com a chamada "descatolinização" do país e o crescimento demográfico das denominações evangélicas, acompanhado de novas estratégias de atuação, dentre elas a conquista de mais espaço político. A apropriação da defesa da laicidade, não pelo viés de apartação entre Estado e religião, mas de garantia da presença de "todas" as religiões nele. 
No que tange a tramitação e aprovação desses projetos reacionários e a consequente perda de autonomia do campo educacional há, para nós, estreita relação com uma crescente redução da laicidade do Estado. Essa afirmação é baseada na ideia de que as posições do campo educacional frente a outros campos como o político e/ou religioso, têm na laicidade do Estado um elemento central para a garantia de sua autonomia diante da produção de suas políticas. Ou seja, a dinâmica e a organização do campo educacional brasileiro, bem como seu grau de autonomia frente a agentes e fatores externos constituem o componente determinante para o funcionamento da produção das políticas educacionais. Nesse sentido, o efeito de intrusão e a heteronomia presentes, através, por exemplo, da ação dos agentes religiosos, têm implicação na produção de suas políticas e na diminuição do grau de laicidade do Estado brasileiro. Por sua vez, essa interferência no processo de laicização do país tem relação estreita com o nível de Democracia estabelecido e vivenciado no país. Estamos assistindo nos últimos tempos no Brasil a interferência direta de ações combinadas entre católicos e evangélicos no campo educacional. Tais ações vêm congregando outros setores conservadores, com interesses diversos, e promovendo um avanço da pauta conservadora, especialmente através da educação.

No quadro recente a educação vem sofrendo com as posturas e manobras assumidas pelos que se propõem fazer retroceder políticas e movimentos de ideias progressistas, e que, para tal, buscam imprimir um domínio sobre o papel da escola, sobre a ação pedagógica dos docentes e sobre os conteúdos programáticos. Nesse sentido, entendemos que a defesa de uma educação laica é também a defesa de uma educação democrática e pública, que enfrenta as diversas formas de privatismos impostas a nossa educação ao longo de nossa história.

Assim, mais uma vez destacamos a importância de uma escola e uma educação laica. Nessa perspectiva, a escola passa a ser entendida como um espaço estratégico para o diálogo e para o combate a preconceitos oriundos especialmente desses discursos religiosos e deterministas. Exatamente por seu potencial na desconstrução de estereótipos, de modelos rígidos e tradicionais e de discriminações que ela vem sendo ao longo de nossa história uma das principais instituições disputadas por religiosos e conservadores. O que significa necessariamente negar a escola "neutra" e defender uma escola que promova os valores básicos que permitem a própria existência de uma ordem democrática. Como afirmou Ranquetat Júnior (2008): “o Estado laico não é neutro, pois advoga uma determinada visão de mundo e defende certos valores como a democracia, os direitos humanos, a igualdade e a liberdade".

Ou seja, a educação laica assume uma tarefa pedagógica e positiva, abordando valores e princípios que propiciam o questionamento e o rompimento com uma série de entraves morais e colaboram para a abordagem de temas como gênero e sexualidade no segmento educacional sem interdições. Além disso, tais pressupostos apontam para a ideia do campo educacional enquanto um espaço de promoção da cultura e do reconhecimento da pluralidade das identidades e dos comportamentos relativos às diferenças. 


\section{Referências:}

AQUINO, F. O avanço da Ideologia de Gêneros. 2012. Disponível em: <http://cleofas.com.br/o-avancoda-ideologia-de-generos/>. Acesso em: 23 de março de 2019

BRASIL. Constituição de 1988, de 05 de outubro de 1988.

BLANCARTE, R. El Estado laico. México: NostraEdicionoes, 2008.

. Los retos de lalaicidad y lasecularizaciónenel mundo contemporáneo. México, D. F.: El Colegio de México, Centro de Estudios Sociológicos, 2008a.

El porqué de un Estado laico. In BLANCARTE, R. (Org.). Los retos de laicidad y lasecularizaciónenel mundo contemporáneo. 1. ed. México, D. F.: El Colégio de México, Centro de Estudios Sociológicos. 2008b.

CANÇÃO NOVA. Ideologia de gênero, conheça seus perigos e alcances. Destrave. [S.1.], 20 nov. 2012. Disponível em: 〈http://destrave.cancaonova.com/ideologia-de-genero-seus-perigos-e-alcances/>. Acesso em: 22 de março. 2019.

CÂMARA DOS DEPUTADOS. Projeto de Lei 1.411/2015. Tipifica o crime de Assédio Ideológico e dá outras providências. Brasília: 06 mai. 2015c. Disponível em: <http://www.camara.gov.br/proposicoesWeb/fichadetramitacao?idProposicao=1229808>. Acesso em: 28 out. 2016.

CARNEIRO, S. S. Ensino Religioso no Rio de Janeiro: um bom caso para pensar religião, direitos humanos e as relações entre estado e Igreja. In Religiões em conexão: números, direitos, pessoas. Áskesis, v.6, n.1, Janeiro/Junho - 2017.

COELHO, M.M. Padre explica o que é a ideologia de gênero. Coluna Notícias - Canção Nova. Aparecida/SP, 23 março. 2019. Disponível em: <http://noticias.cancaonova.com/brasil/padre-explica-oque-e-a-ideologia-de-genero/>. Acesso em: 28 maio. 2017.

CUNHA, Christina Vital da; MENEZES, Renata de Castro. (Org.) Comunicações do ISER. Rio de Janeiro, n69, ISER, 2014.

CUNHA, Luiz Antônio. O projeto reacionário de educação. [S.1.], 2016?. Disponível em: 〈http://luizantoniocunha.pro.br/uploads/independente/1-EduReacionaria.pdf>. Acesso em: 10 dez. 2016.

O Legado da ditadura para a educação brasileira. Educação e Sociedade. Rio de Janeiro: UFRJ, v. 35, p. 357-377, 2014 b.

A laicidade em disputa: religião, moral e civismo na educação brasileira. Teias. Rio de Janeiro: v. 14 , p. 5, 2014c.

Educação e religiões: a descolonização religiosa da escola pública. $1^{a}$ ed. Belo Horizonte: Mazza Edições, $2013 b$.

. A difícil laicidade na educação pública. In: BERTUSSI, Guadelupe Teresinha; OURIQUES, Nildo. (Org.). Anuário Educativo Brasileiro: visão retrospectiva. 1ed.São Paulo: Cortez, v. 1, p. 105-122, 2011.

. A luta pela ética no ensino fundamental: religiosa ou laica? Cadernos de Pesquisa. São Paulo: v. 39,

n. 137, p. 401-419. Ago. 2009. Disponível em: $<$ http://www.scielo.br/scielo.php?script=sci_arttext\&pid=S0100-

$15742009000200005 \& \operatorname{lng}=$ en\&nrm=iso>. Acesso em 18 out. 2016.

Sintonia oscilante: religião, moral e civismo no Brasil - 1937/1997. In: CONGRESSO LUSOBRASILEIRO DE HISTÓRIA DA EDUCAÇÃO, 4, 2006, Uberlândia. IV Congresso Luso-Brasileiro de História da Educação. Uberlândia: COLUBHE, 2006. 
.; OLIVA, C. E. Sete teses equivocadas sobre o Estado Laico. In: Conselho Nacional do Ministério Público. (Org.). Ministério Público em Defesa do Estado Laico. 1ed. Brasíla: CNMP, v. 1, p. 207-227, 2014.

.; FERNANDES, Vânia. Um acordo insólito: ensino religioso sem ônus para os poderes públicos na primeira LDB”. Educação e Pesquisa. São Paulo: v. 38, n. 4, out/dez. 2012. Disponível em: <http://www.scielo.br/pdf/ep/v38n4/en_aop753.pdf>. Acesso em 28 out. 2016.

CRUZ, L.C. L. O perigo do "gênero" em educação. Sítio do Movimento Pró-Vida Anápolis. Anápolis: 2014. Disponível em: <http://www.providaanapolis.org.br/index.php/todos-os-artigos/item/428-o-perigodo-genero-em-educacao>. Acesso em: 11 mar. 2019.

FERNANDES, Maria das Graças Melo. O corpo e a construção das desigualdades de gênero pela ciência. Physis, Rio de Janeiro/RJ, v. 19, n. 4, p. 1051-1065. 2009. Disponível em: $<$ http://www.scielo.br/scielo.php?script=sci_arttext\&pid=S0103-

73312009000400008\&lng=pt\&nrm=iso>. Acesso em: 22 de março. 2019

GÓES, Bruno. Deixamos a teoria da evolução entrar nas escolas', disse Damares em entrevista de 2013. 9 de janeiro de 2019. Disponível em: <https://oglobo.globo.com/sociedade/deixamos-teoria-da-evolucaoentrar-nas-escolas-disse-damares-em-entrevista-de-2013-23357207> Acesso em: 26 de março de 2019.

JUNQUEIRA, R. D. Ideologia de gênero: a gênese de uma categoria política reacionária - ou: como a promoção dos direitos humanos se tornou uma "ameaça à família natural". In: RIBEIRO, Paula Costa; MAGALHÃES, Joanalira C. (orgs). Debates contemporâneos sobre Educação para a sexualidade. Rio Grande: Ed. da FURG, 2017. Disponível em: goo.gl/MUN9tM

KOREN, J.C. Silas Malafaia, a Associação Vitória em Cristo e a defesa da família tradicional. Revista Espaço Acadêmico, Maringá/PR, n.175, Universidade Estadual de Maringá, dez. 2015.

MENEZES. R. Religiões, números e disputas sociais. In VITAL DA CUNHA, C.; MENEZES, R.C. (Org.). Religiões em conexão: números, direitos, pessoas. Comunicações do ISER, Rio de Janeiro/RJ, n69, ISER, 2014.

ORO, P. A. A laicidade no Brasil e no Ocidente: Algumas considerações. Civitas - Revista de Ciências Sociais, Fortaleza/CE, v. 11, n. 2, p. 221-237. 2011.

PAINS, Clarissa. 'Menino veste azul e menina veste rosa', diz Damares Alves em vídeo. 03 de janeiro de 2019. Disponível em: <https://oglobo.globo.com/sociedade/menino-veste-azul-menina-veste-rosa-dizdamares-alves-em-video-23343024>Acesso em: 26 de março de 2019.

PIERUCCI. F. A. religião como solvente - uma aula. Novos Estudos, São Paulo/SP, n. 75, CEBRAP, jul. 2006.

RANQUETAT JR., César A. Laicidade, laicismo e secularização: definindo e esclarecendo conceitos. Revista Tempo da Ciência v. 15, n. 30 , $2^{\circ}$ semestre 2008.

REDAÇÃO. Oração de Magno Malta abre pronunciamento de Bolsonaro. 28 de outubro de 2018. Disponível em: <https://www.gospelprime.com.br/oracao-magno-malta-jair-bolsonaro/>Acesso em: 26 de março de 2019.

TORNIELlI, A; GALEAZZI, G. Papa Francesco: questa economia uccide. Collana Religione, Serie Saggistica, Piemme - Italia, 2015.

UOL. Olavo de Carvalho questiona se Terra orbita o Sol; o que diz a ciência? 09 de janeiro de 2019 Disponível em: $<$ https://noticias.uol.com.br/ciencia/ultimas-noticias/redacao/2019/01/09/o-que-a-cienciadiz-sobre-a-terra-ser-o-centro-do-universo.htm>Acesso em: 26 de março de 2019. 


\section{Notas:}

i Doutora em Política Social pela UFF. Especialista em gênero e sexualidade pela Universidade do Estado do Rio de Janeiro- UERJ. Mestre em educação pela Universidade Federal do Rio de Janeiro -UFRJ. Socióloga - UFRJ. Professora assistente desde 2014 da Universidade Estácio de Sá. Colaboradora do Observatório da Laicidade na Educação (OLÉ).

ii Doutoranda em Educação pelo PPGEDU-UFF. Mestre em Ensino de História pela Universidade Federal do Rio de Janeiro (2016). Especialização em Gênero e Sexualidade pela Universidade do Estado do Rio de Janeiro (2014). Graduada em História também pela Universidade do Estado do Rio de Janeiro (2008), É professora da Secretaria Municipal de Educação do Rio de Janeiro (2009 -hoje) tendo sido também professora da Secretaria Estadual de Educação do Rio de Janeiro e da rede particular de ensino. Colaboradora do Observatório da Laicidade na Educação (OLÉ).

iii $\mathrm{O}$ termo designa o processo de mudança pelo qual a sociedade deixa de ter instituições legitimadas pelo sagrado, baseadas no ritualismo e na tradição, tornando-se cada vez mais profana (ou secular), baseada na individualidade e/ou na racionalidade.

iv Para mais informações sobre como as políticas anti-gênero afetaram as políticas educais ver Mendonça, Amanda André de. Estado, religião e democracia: reflexões a partir dos debates sobre "ideologia de gênero" no Plano Nacional de Educação. Tese submetida ao Programa de Pós Graduação em Política Social, Escola de Serviço Social, da Universidade Federal Fluminense UFF, 2017. Disponível em: http://politicasocial.uff.br/?ddownload=2343

${ }^{v}$ Referência a unidade de atuação de grupos políticos com origens diversas, mas que se encontram em algumas pautas, como as tratadas neste texto.

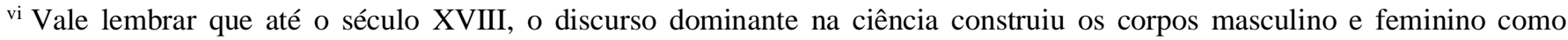
versões hierárquicas e verticalmente ordenadas de um único sexo.

vii Expressão cunhada por determinadas lideranças católicas em seus textos e discursos em referência a setores do feminismo que defendem o aborto, a desconstrução dos papéis sociais e a livre orientação sexual. $\mathrm{O}$ termo estabelece uma distinção entre feministas que defendem a igualdade de direitos, as quais essas lideranças religiosas respeitam e consideram a luta, e segmentos que visam destruir com a família.

viii Expressão cunhada por determinadas lideranças católicas em seus textos e discursos em referência aos pesquisadores/as, especialistas, teóricos/as e indivíduos que são referências nos estudos de gênero.

ix Doutor em engenharia mecânica pela UNESP e Mestre na área pela UNIFEI (Universidade Federal de Itajubá). Possui um programa na Rádio Canção Nova, "No Coração da Igreja", e dois programas na TV Canção Nova, "Escola da Fé" e "Pergunte e Responderemos". É professor de História da Igreja do Instituto de Teologia Bento XVI na Diocese de Lorena. Escreve artigos e publica notícias no Portal Canção Nova e no site da Editora Cléofas.

${ }^{x}$ Psicóloga clínica brasileira, cristã, especialista em sexualidade humana com pós-graduação em saúde mental. Marisa Lobo é também colunista do Gospel+, um site de notícias evangélico. Em 2013, Marisa filiou-se ao Partido Social Cristão do Paraná (PSC).

xi Para mais informações sobre a História do Escola Sem Partido e sua relação com o fundamentalismo religioso ver MOURA, Fernanda Pereira de. "ESCOLA SEM PARTIDO": Relações entre Estado, Educação e Religião e os impactos no Ensino de História. Dissertação de Mestrado submetida ao Programa de Pós-Graduação em Ensino de História, Instituto de História, da Universidade Federal do Rio de Janeiro - $\quad$ UFRJ, $2016 . \quad$ Disponível em:https://educapes.capes.gov.br/bitstream/capes/174584/2/Disserta\%C3\%A7\%C3\%A30\%20Fernanda\%20Pereira\%20de\%20 Moura.pdf.

xii As atualizações sobre a quantidade de PLs é feita por Fernanda Moura, Renata Aquino e Diogo Salles. O levantamento até janeiro de 2018 encontra-se disponibilizado no site https://pesquisandooesp.wordpress.com/. O novo levantamento de janeiro de 2019 ainda não está disponível, mas será disponibilizado no novo site da Frente Nacional Escola Sem Mordaça a ser lançado em breve.

xiii Todas as falas de Miguel Nagib em audiência pública citadas neste texto foram retiradas dos áudios originais disponíveis em <http://www2.camara.leg.br/atividade-legislativa/comissoes/comissoes-temporarias/especiais/55a-legislatura/pl-7180-14valores-de-ordem-familiar-naeducacao/reunioes/pesquisa/videoArquivo?codSessao=58813\&codReuniao=46280\#videoTitulo $>$. Acesso em 22/02/2019. ${ }^{\text {xiv }}$ Para maiores referências: COLOMBO, Luiza Rabelo. Reflexões sobre o escola sem partido e seu avanço no campo das políticas educacionais brasileiras. Entropia, vol. 2, n. 3, jan-jun, 2018.

${ }^{\mathrm{xv}}$ Atual ministro da Economia. 
xvi Todas as falas de Jurecê e Calil citadas no texto foram extraídas do Podcast Professores Contra o Escola Sem Partido episódio Dossiê Ricardo Veléz Rodriguez disponível em: https://profscontraoesp.org/2018/12/20/pcesp-podcast-extra-6dossie-ricardo-velez-rodriguez/

xvii Para maiores informações sobre ele recomendamos a matéria no blog Avaliação Educacional do Luiz Carlos de Freitas. Disponivel em: https://avaliacaoeducacional.com/2018/10/12/stavros-xanthopoylos/

xviii https://educacao.estadao.com.br/noticias/geral,mec-fica-a-deriva-apos-6-recuos-e-15-exoneracoes-general-deve-ir-para-oinep, 70002769478. Acesso em 18/03/2019

${ }^{\text {xix } U m ~ n o m e ~ d i g n o ~ d e ~ n o t a ~ e ́ ~ o ~ d e ~ O r l e y ~ J o s e ́ ~ S i l v a ~ q u e ~ f o i ~ n o m e a d o ~ c o m o ~ a s s e s s o r ~ p a r a ~ a s s u n t o s ~ l e g i s l a t i v o s ~ e ~ e ́ ~ a l e ́ m ~ d e ~}$ pastor, é um dos intelectuais orgânicos do Escola Sem Partido e dos movimentos anti-gênero.

xx Disponível em: revistaforum.com.br/politica/futura-secretaria-executiva-do-mec-defende-educacao-baseada-na-palavra-dedeus/. Acesso em: 20/03/2019 